\title{
Application of Remanufacturing Technology on Military Aero-engine
}

\author{
L.L WANG \& Y.X CHEN \\ The Equipment Management and Safe Engineering Institute Air Force Engineering University, Xi 'an
}

\begin{abstract}
Remanufacturing technology is the advanced technology of the surface physical engineering, the technology can improve the physical indicators of material, and make waste materials to meet the new requirements on the use of the products, it has an important role in energy saving material and environmental protection. Aimed at using present situation and problems of the military aero-engine, the paper take a certain type of military aero-engine as an example, detailed analysis the feasibility and necessity of this type engine using remanufacturing technology, and the specific implement process.
\end{abstract}

KEYWORD: Remanufacturing Technology; Aero-engine; Life-cycle

\section{INSTRUCTIONS}

With the rapid development of science and technology, more and more new technology 、 new method are applied to reduce the equipment lifecycle cost. Remanufacturing technology is the outstanding representatives. At present, remanufacturing technology has been widely used in all kinds of civil electrical and mechanical equipment. Due to the extreme importance of military aircraft in the military aero-engine, cause less remanufacturing technology application in the field of aero-engine, that is to say, the application in the field of aviation is in its infancy. This paper choose a certain type of military aero- engine as discussed remanufacturing technology applied in the field of aviation, the reason is: 1 . The engine unit price of 10 million yuan; 2 . The provisions of the engine service life only 800 hours, only for a quarter of the airframe; 3 . The engine is combined with compressor, combustion chamber and turbine, nozzle and other attachment. All the main parts adopt high quality alloy material, the design safety margin reached $100 \%$, it has room for remanufacturing.

\section{RELEVANT CONCEPTS}

\subsection{The remanufacturing technology}

From 2005, China's state council issue a number of files in a row, emphasize "remanufacturing technology". Remanufacturing engineering generally refers to take equipment life cycle theory as a guide, take the leapfrog equipment to promote as the goal, take high quality, high efficiency, energy saving, material saving, environmental protection as the guidelines, by means of advanced technology and industrialization, a series of measures of repairing and renovating the leapfrog equipment or the engineering activities[1]. Equipment manufacturing methods mainly include remanufacturing recovery and remanufacturing upgrade. The main characteristic of remanufacturing is remanufacturing product quality and performance meet or exceed the new product, about $50 \%$ of the cost for new products, $60 \%$ energy saving, material saving more than $70 \%$, contributed significantly to protect resources and environment[2].

\subsection{Features of remanufacturing product life cycle}

Remanufacturing product life cycle is "development - use - regeneration", its logistics is a closed loop system, compared with the traditional product life cycle open loop system of "development-use-scrap", it has great extension and development.

Military remanufacturing aero-engine because of its characteristics of remanufacturing products, its life cycle (as shown in figure 1) is different from the life cycle of ordinary military aero-engine (as shown in figure 2).

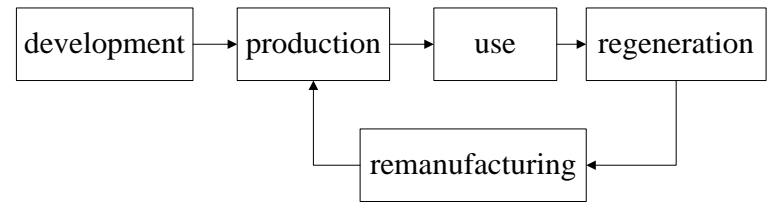

Figure1 Life cycle of military remanufacturing aero-engine 


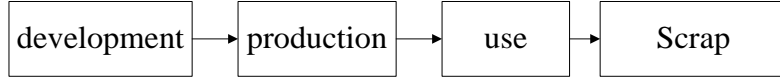

Figure2 Life cycle of ordinary military aero-engine

Development, production and use phase is general steps of ordinary military aero-engine. The different of military remanufacturing aero-engine and ordinary military aero-engine is that the scrap phase of ordinary military aero-engine discarded into regeneration and remanufacturing phase, and production, use, recycling, remanufacturing formed a closed system. This shows that remanufacturing engine itself can take remanufacturing process again.

\subsection{The key technology of remanufacturing}

At present, a lot of research on the key technology of remanufacturing both at home and abroad, after summing up, the main has the following kinds:

\subsubsection{The micro/nano surface engineering technology}

Micro/nano surface engineering technology is the technology referred which obtain micro/nano structure or micro/nano composite coating from the materials or components surface [3]. The main effect of this technology performance in: first, change the performance of the material surface, such as changes of hardness, strength and abrasion resistance on the material surface, or make the material surface have automatic repair function, etc.; second, the parts design material selection scope is expanded, make the ordinary materials with the performance of the specific materials through the nano coating on the surface layer.

\subsubsection{Cleaning technology}

According to the cleaning location, cleaning purpose and such as the complexity of the materials, the use of cleaning technology and method during the cleaning process is different also, it need to apply a variety of cleaning method at the same time usually. The cleaning methods mainly include: gasoline cleaning, chemical cleaning agent to clean, scrub or steel brush wash, high pressure spray cleaning (generally), sand blasting, electrolytic cleaning, gas cleaning, ultrasonic cleaning, etc. The selection of equipment should be based on standards, requirements, environmental protection, cost and manufacturing sites of remanufacturing to determine.

\subsubsection{The flaw detection technology [4]}

The flaw detection technology which suitable for use on this engine is mainly nondestructive flaw detection, nondestructive flaw detection is the technology which to use instruments and equipment to inspect and detect the defect of parts or components under the condition without detection object destruction or damage.The main detection methods are:

(1)Magnetic powder detection, this method is not subject to any restrictions on the size and shape of the parts, can be found the defects on the ferromagnetic material such as cracks, porosity, inclusions;

(2)Eddy current flaw detection, this method use the interaction of the electromagnetic field and the metal being measured, determine the metal surface defects by the size of the eddy current, such as surface cracks, porosity, etc.;

(3) X-ray detection, this method use the attenuation of rays through the process of material to detect parts internal defects;

(4) Fluorescence detection, this method use fluorescent material penetrate the surface of the object to be tested, under ultraviolet light, the defect image is appeared, in order to find the material surface defects, the method is not affected by magnetic material;

(5)LCD inspection, to judge the defects by using the LCD color change, for sheet parts can use the LCD color changing with temperature sensitivity check defects; For other parts can use the LCD color change color after contaminated to determine parts surface crack, crystal corrosion, etc.

\section{THE MAIN PROBLEMS IN MILITARY AERO- ENGINE MAINTENANCE}

\subsection{The current maintenance mode of military aero- engine}

At present, military aero-engine apply life-cycle management, it calculate the whole life cost and management as a whole. The use time of engine is mainly prescribed by the design and production units, the maintenance mainly divided into three levels, after many renovations, the total life achieve mandatory, namely scrapping, and there is no scientific test whether the engine technical status is good, the component parts are in good condition.

\subsection{The main problems}

\subsubsection{The feasibility argument about remanufacturing technology in Air Force is still in its infancy}

As is known to all, the plane is different from the car. If automobile engine of the car failure, it can be parked on the side of the road for repair, but if the plane engine failure, light lead to accident symptom, weigh happen level accident, economic losses would not estimate. Therefore, this causes the blind spot that remanufacturing technology in the field of aviation, and leads to the insufficient understanding of the project enormous economic and military 
benefits in aviation, the feasibility argument is also stalled.

\subsubsection{Theoretical system of remanufacturing is still imperfect}

At present, the framework build of military remanufacturing theories is still at the initial stage, there is no specific book to introduce systematically. only military armored force engineering institute founded the remanufacturing system, and all the concrete results about the equipment remanufacturing etechnoloty and the application is less, military authorities only Xu Bin-shi [1][5][6][7] and others.

\subsubsection{The military technical personnel know so little of remanufacturing products}

Remanufacturing product use very little in military, people have doubts about remanufacturing product performance, and people have no cognitive about the process and technical of remanufacturing technology; at the same time, the research on maintenance procedures and use of the provisions of remanufacturing product is still in its infancy.

\section{REMANUFACTURING TECHNOLOGY IN USE AND ANALYSIS OF A CERTAIN TYPE OF MILITARY AERO-ENGINE}

\subsection{The reason of the type engine use remanufacturing technology main problems}

After this type engine use and scrap, generally adopt sealed treatment, now it is sealed a huge number of the engine; and the demand of engine is very big, it often appear the grounded phenomenon because of the plane for airborne engine to life or engine batch fault. At the same time, this type engine conform remanufacturing technology standards:

(1)This type engine is durable products. New products general design life reach for 800 hours, overhaul life is up to 300 hours for the first time. After adopt remanufacturing technology, remanufacturing product total life should be more than 800 hours.

(2)This type engine scrapping is functional. That most discarded engine technical status is in good condition, just because of the design and production requirements, had to be scrapped.

(3)This type engine is in accordance with the requirements of standardized production, the parts are interchangeable.

(4)This type engine must single value, product recovery value is high.

(5)Adopt remanufacturing engineering, to restore the performance of the product cost is low.

\subsection{The advantages of this type engine carry out remanufacturing technology}

\subsubsection{Save resources}

Each this type new engine's price is above 10 million yuan, many parts materials are rare metal, once the engine scrap, rare metal are also failure, it cause the waste of money and resources. If these rare metals can make full use of, the economic benefit is very obvious.

\subsubsection{To save time during the war}

The equipment amount of this engine is large, but parts are small. As time goes on, the scrap quantity increases. In the event of war, it is very difficult to emergency product this engine in order to meet operational needs. However, if the engine adopts the remanufacturing technology, the shorter production cycle and the less cost can quickly meet the needs of the war.

\subsubsection{The technical reserve enough}

At present, remanufacturing technology has been fully used in the field of civil and some military fields. The reliability and maturity of all kinds of remanufacturing technology got fully verified, it belongs to "shelf technology". We can apply these mature reliability technology in the field of military aviation.

\subsection{The remanufacturing process flow[8] of the type engine}

The remanufacturing process flow of the type engine and the regular overhaul have in common, the biggest difference of both is the engine performance after remanufacturing achieve even more than the original product. Most process of engine remanufacturing is removed, classification of cleaning, remanufacturing processing or replace new parts, assembly and test, etc. As shown in figure 3.

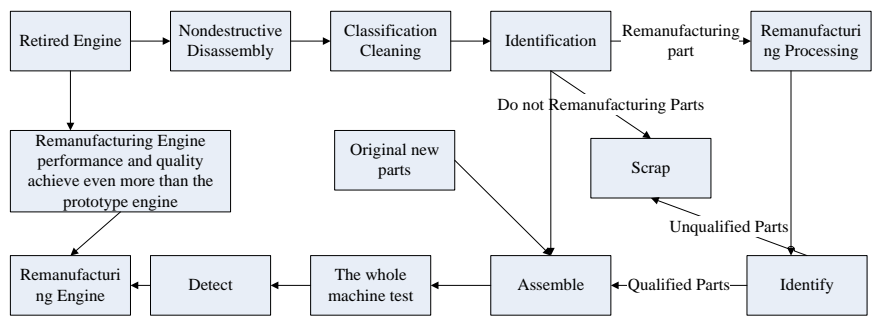

Figure3 Remanufacturing process flow figure of the type engine

\subsection{The concrete implementation}

\subsubsection{The technical evaluation}

For the engine which technology is in good condition before scrap, first carries on the detailed technical performance evaluation; and inventory 
check each resume file of engine, make sure the engine has been no serious fault in use process, in order to determine the engine does have the capacity to remanufacturing and value.

\subsubsection{The disassembly cleaning}

Due to long-term work, dust, oil and wear filling between the engine each component. First, clean the engine block surface, it can be used high pressure jet cleaning, local gasoline cleaning and so on.

After cleaning the engine surface, the following work is dismantling, obvious deformation, high temperature burns, severe wear parts are no longer used, all these don't have to wash; At the same time, eliminate parts directly, such as bearings, gaskets, etc. The components cleaning after dismantling is mainly include removing oil, rust, carbon deposit and other content. For different parts must adopt different cleaning method, in order to convenient for further inspection work:

(1) Compressor is composed of compressor blades and compressor box, long-term high speed rotating, there are all sorts of foreign substance (mainly insects) into marks, compressor blade must be clean, it can use gasoline to clean. Because contact a large amount of water vapor, compressor box often occur corrosion, the main method go to rust is mechanical method, chemical pickling method and electrochemical acid corrosion, etc. The part is better to use electrochemical acid etching method.

(2) Combustion chamber is mainly composed of fuel nozzle and chamber main body, the machine is fuel combustion chamber, carbon deposit is very serious. Now often use mechanical method, chemical method and electrolysis method to removal carbon deposit. The chemical method is suitable in here, this method does not damage the performance of the component itself.

(3) The turbine is mainly composed of turbine blades and turbine box. Turbine blades and turbine box are mainly polluted by high temperature calcination and carbon deposit, it is no longer used the blade and box which can see traces of the burning, only the blade and box which carbon deposit can clean by the chemical method.

(4) Nozzle is Polluted by high temperature calcination and carbon deposition, carbon deposit can be removed with chemical method, but deformation due to the high temperature is no longer used.

(5)The shaft is high temperature and high speed components, deformation, burning and severe abrasion marks is no longer cleaning. Only the oil can be combination with chemical cleaning fluid and ultrasonic cleaning.

\subsubsection{Parts inspection}

Because the engine's parts are precision assembly, therefore, before the inspection, it should be use precision measuring tools to measure the size of the parts first, and it must meet the requirements of each part resume file size range, otherwise, the parts must be eliminated. The inspection result should be a detailed record on record files in the parts.

\subsubsection{The restore performance processing of parts}

The parts for cleaning and after inspection qualified can take various measures to make its restore original technical performance. Take the widely used mature technology to reduce production cycle and cost. Main technology is advanced surface technology and composite surface technology, used to repair and strengthen the failure surface of scrap parts.

According to the characteristics of the type engine work conditions, mainly high temperature, high speed, etc., we have a choice of different parts to different ways of technology processing.

Turbine blades and the compressor blade is the core of the engine components, whether their success for remanufacturing or not have a vital role on the whole engine remanufacturing. Turbine blades and the compressor working speed is high, the normal scope of work in 5400-11110 revolutions per minute, while working blade by centrifugal force is very large; At the same time, it also bear the high temperature of $900^{\circ} \mathrm{C}$ or so, the work environment is very bad. Aim at such a situation, we can adopt ceramic thermal barrier coatings (TBCS) technology on the blade surface. The technology can decrease the temperature of metal surface, prolong its service life.

Nozzle can be used carbon deposit proof coating.

Engine accessories catheter can be used spraying technology for reinforcement.

There are many technology can achieve the same effect. At the same time, the use of these technologies will not change the overall dimensions of the parts and not affect the assembly use of parts.

\subsubsection{The difference between remanufacture engineering and engine life extension project}

Aim at no to the life of the engine, Engine life extension project can extend the provisions of the engine life by changing the "short board" (life is short, use easy damage) parts, and detect the work reliability of the machine through work a long period of time. At present, engine life could be extended by 100-200 hours.

Remanufacturing engineering is aimed at the engine with the life of scrap but good technical performance, through a variety of high and new technology to restore its original reliability and technology performance. It can even be already 
through life extension processing engine to carry out the work.

\section{CONCLUSION}

As an important part of green design, green manufacturing technology, remanufacturing engineering has a bright prospect, it has important implications to reduce the consumption of natural resources, save material, reduce environmental pollution and so on. Adopt the requirement of sustainable development strategy, especially in military products, it should strengthen and emphasize the basic research on remanufacturing engineering related theory and technology. Remanufacturing technology applied in aviation will be effective to save money, save resources; at the same time, it can enhance battle combat effectiveness, and achieve economic and military double benefits.

\section{REFERENCES}

[1] XU Bin-shi, LIU Shi-can. Develop equipment remanufacturing engineering, promote circulation economy construction. Technology and management of construction machinery, 2006. 1:51- 55.

[2] XU Bin-shi. The theory and technology of equipment remanufacturing engineering. Beijing: national defence industry press, 2007:11-12.

[3] XU Bin-shi. Equipment remanufacturing technology. China equipment engineering, 2007.11:61.

[4] Air force aviation engineering dictionary. China science and technology press.

[5] XU Bin-shi. Development the equipment remanufacture, improve military equipment capability of support and capacity of fighting. Journal of Academy of Armored Force Engineering.2006, 20 (3): 1-5.

[6] XU Bin-shi. Development status and prospect of green remanufacturing engineering. Engineering Science.2011, $13(1): 4-9$.

[7] XU Bin-shi. Engineering Management Problems of Remanufacturing Industry. China Surface Engineering. 2012, 25 (6):107-111.

[8] SHI Pei-jing, XU Bin-shi, LIU Shi-can, Zhu Shaohua. Disassembling design for equipment remanufacturing engineering. Journal of Academy of Armored Force Engineering. 2007, 21 (5): 12-15. 